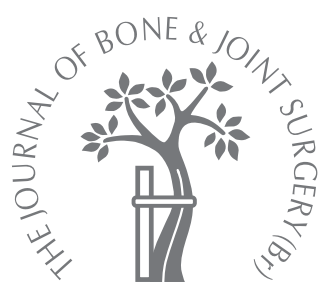

H. Wallander,

S. Larsson,

T. Bjönness,

G. Hansson

From Uppsala

University Hospital,

Uppsala, Sweden

\title{
Patient-reported outcome at 62 to 67 years of age in 83 patients treated for congenital clubfoot
}

The outcome in 83 patients with congenital clubfoot was evaluated at a mean age of 64 years using three validated questionnaires assessing both quality of life (short-form (SF)-36 and EQ-5D) and foot and ankle function (American Academy of Orthopaedic Surgeons (AAOS) Foot and Ankle questionnaire). In SF-36, male patients scored significantly better than male norms in seven of the eight domains, whereas female patients scored significantly worse than female norms in two of the eight. Male patients scored better than male norms in both the EQ-5D index $(p=0.027)$ and visual analogue scale (VAS) $(p=0.013)$, whereas female patients scored worse than female norms in the VAS $(p<0.001)$. Both male and female patients had a significantly worse outcome on the AAOS Core Scale than did norms. There was a significant correlation for both genders between the SF-36 Physical Component Summary Score and the AAOS Core Scale.

The influence on activities of daily life was limited to foot and ankle problems in all patients, and in females there was an adverse effect in physical aspects of quality of life.

Congenital clubfoot (congenital talipes equinus varus, $\mathrm{CTEV}$ ), with an estimated global incidence of one in 1000 newborn children, ${ }^{1}$ affects quality of life and the function of the foot. ${ }^{2,3}$ Residual impairment of function is related to persistent deformities due to inadequate initial reduction, ${ }^{4,5}$ relapse of deformities ${ }^{6,7}$ and complications of treatment. ${ }^{8-11}$ Furthermore, degenerative changes, due to residual deformity, may develop in middle age, with further adverse effects. ${ }^{3,12}$ Therefore, evaluation of the long-term results of treatment cannot be considered reliable unless patients have reached middle age or beyond. There are few reports on such long-term outcomes in CTEV. ${ }^{3,13-16}$

We reviewed a group of patients over 60 years of age who had been treated for CTEV in infancy, using generic instruments for the assessment of quality of life in general and a specific foot and ankle instrument for assessment of function.

\section{Patients and Methods}

In southern Sweden in the 1940s, patients with congenital or acquired deformities of the extremities were commonly treated at one of two special centres in Gothenburg or Helsingborg. Between 1940 and 1944, they treated a consecutive series of 106 patients with CTEV who were born between 1939 and 1944. In 1974, Bjönness ${ }^{15,17}$ published an outcome study of 95 of them. We reviewed all their records, which confirmed at the outset that no teratological clubfeet had been included. Through tax authorities and regional archives, the 89 patients still alive in 2006 were traced and invited to participate in the study; 83 (63 men and 20 women) agreed and their demographic and treatment data are shown in Table I. Six patients did not participate, including two who did not reply to the invitation, three who declined to participate, and one who completed only the foot-specific instrument and was therefore excluded. All but two lived in Sweden. Approval for the study was obtained from the regional Ethics Committee.

The initial treatment was non-operative in $116(96 \%)$ (Table I). A total of 15 feet (12\%) were treated by casting alone and the remaining $106(88 \%)$ were treated operatively. The mean number of operations on each foot, either male or female, was 2.1. Some patients had more than one procedure on the same occasion. The most common operation was lengthening of the tendo Achillis (100 procedures) and the most common bony operation was derotational osteotomy of the distal tibia (31 procedures). Late surgery, that is, after the age of 30 years, was performed in only one patient, who underwent talonavicular arthrodesis. 
Table I. Baseline data on 83 patients treated for congenital clubfoot

\begin{tabular}{|c|c|}
\hline \multicolumn{2}{|l|}{ A Demographic data } \\
\hline Number of patients & 83 \\
\hline Number of clubfeet & 121 \\
\hline \multicolumn{2}{|l|}{ Laterality } \\
\hline Unilateral:bilateral & $45: 38$ \\
\hline \multicolumn{2}{|l|}{ Gender } \\
\hline Male:female & $63: 20$ \\
\hline Age at initial treatment ${ }^{*}$ (mths) & 4.0 (1 to 24$)$ \\
\hline Age at follow-up ${ }^{*}(y r s)$ & 64.0 (62 to 67$)$ \\
\hline B Treatment & Number of feet \\
\hline Non-operative treatment & 15 \\
\hline Surgery & 106 \\
\hline \multicolumn{2}{|l|}{ Initial treatment } \\
\hline Plaster & 79 \\
\hline Brace & 35 \\
\hline Adjusted shoe & 2 \\
\hline Surgical & 2 \\
\hline Unknown & 3 \\
\hline \multicolumn{2}{|l|}{ Number of operations } \\
\hline 1 & 49 \\
\hline 2 & 20 \\
\hline 3 & 20 \\
\hline 4 & 13 \\
\hline 5 & 1 \\
\hline 6 & 2 \\
\hline 7 & 1 \\
\hline Total & 106 \\
\hline
\end{tabular}

All patients were asked to complete three different selfadministered questionnaires: short-form (SF)-36, ${ }^{18,19}$ Euroquol (EQ-5D) ${ }^{20-22}$ and the American Academy of Orthopaedic Surgeons (AAOS) Foot and Ankle Questionnaire. ${ }^{23}$ The SF-36 and EQ-5D are generic instruments, used for assessing quality of life, and the AAOS questionnaire specifically assesses foot and ankle function. The SF-36 allows physical and mental component scores and the EQ-5D comprises health index values and a visual analogue scale (VAS). Finally, patients were also asked to give their opinion on the appearance of their treated feet by answering the question: 'Do you think your treated foot looks normal?', which was one of the questions asked by Bjönness in $1974 .{ }^{15}$

For the SF-36, an age- and gender-matched normal group of 118 men and 37 women was drawn randomly from the Swedish SF-36 norm database $(\mathrm{n}=8930)$. For the EQ-5D, a normal group of 376 men and 393 women aged 60 to 64, was derived from a population-based $\operatorname{study}^{24}(\mathrm{n}=9489)$ in the southeast of Sweden. For the AAOS Foot and Ankle Questionnaire, an age- and gender-adjusted reference group was recruited. An invitation to participate and the questionnaires were sent to a representative group of
394 men and 108 women, with a mean age of 64 years (62 to 67) living in the same area as the study group. There were 206 respondents to the first invitation. A second letter four weeks later generated a further 102 responses, and after another month a third letter provided 26 more responses. The control group therefore consisted of 262 men and 72 women (67\% participation rate) with a mean age of 64 years (62 to 67).

Each clubfoot patient was compared with the age- and gender-adjusted normal groups. For the measurement of the quantitative variables (SF-36, EQ-5D index and VAS, and AAOS score), there were mean and SD calculations. The unpaired $t$-test was used to examine the difference between independent groups, except for the eight domains of SF-36, which were analysed with the Mann-Whitney $\mathrm{U}$ test. The chi-squared test analysed the distribution of outcome in EQ-5D subscales (no, some, extreme) and the distribution of answers (yes/no) to the question about appearance. Linear regression analysis was performed to compare generic and disease-specific instrument outcomes. Probability values of $<0.05$ (two-sided test) denoted statistical significance.

\section{Results}

SF-36 questionnaire. The overall response rate to the SF-36 questionnaire was $93 \%$ (83 of 89). There was an obvious gender-related difference in outcome (Figs 1 and 2). The male patients scored better than the male norm group in all eight domains, and in seven of these the difference was significant ( $p<0.05$, except physical function, Fig. 1$)$. On the SF-36 physical component summary score there was no difference (patients 47.0 (SD 10.3), norm group 44.2 (SD 10.6), $\mathrm{p}=0.089$ ), whereas on the SF-36 mental component summary score male patients had better outcomes than the norm group (patients 55.6 (SD 7.6), norm group 51.6 (SD 9.5), $\mathrm{p}=0.004)$.

Male patients. These patients scored better than the female patients in all eight domains, and in seven the difference was statistically significant $(\mathrm{p}<0.05$, all except role physical, Fig. 3). Also, the male patients had better scores than the female patients on both the two SF-36 summary scores (physical component: $\mathrm{p}=0.009$ and mental component: $\mathrm{p}=0.028$ ).

Female patients. These patients had worse scores than the female norm group in all eight domains, and in two domains the difference was statistically significant (physical function $p<0.001$, bodily pain $p=0.018$, Fig. 2). On the SF-36 physical component summary score there was a significantly worse outcome in female patients than in the norms (patients 39.2 (SD 14.0), norm group 48.7 (SD 9.2), $\mathrm{p}=0.002$ ), whereas on SF-36 mental component summary score no significant difference was found (patients 50.7 (SD 11.1), norm group 50.5 (SD 9.1), $\mathrm{p}=1.00$ ).

EQ-5D questionnaire. The overall response rate of the EQ5D questionnaire was $93 \%$ (83 of 89 ) for Index score and 91\% (81 of 89 ) for the VAS. Male patients scored better 


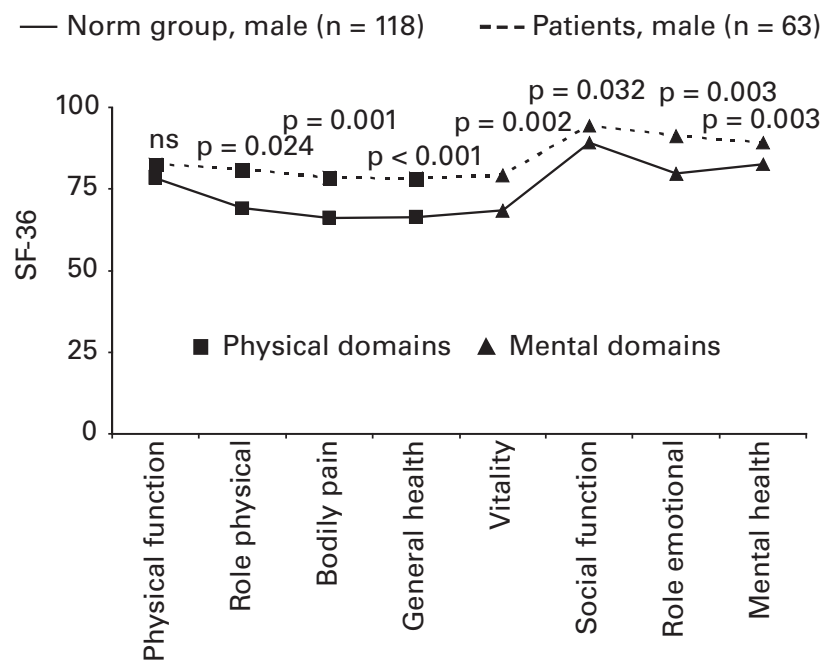

Fig. 1

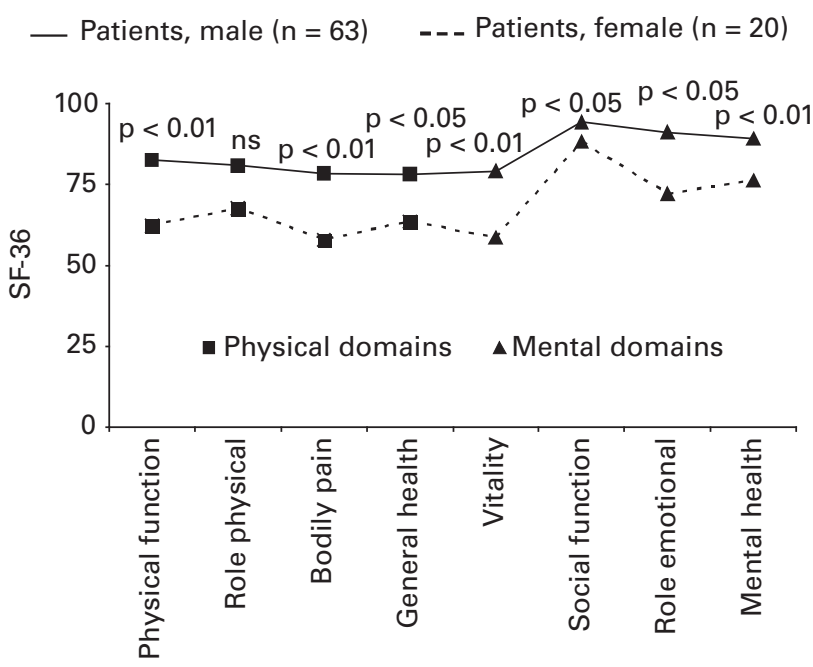

Fig. 3

Short-form 36 used to assess quality of life at the mean age of 64 years in 63 male patients and 20 female patients treated for congenital clubfoot.
— Norm group, female $(n=37) \quad$ - - Patients, female $(n=20)$

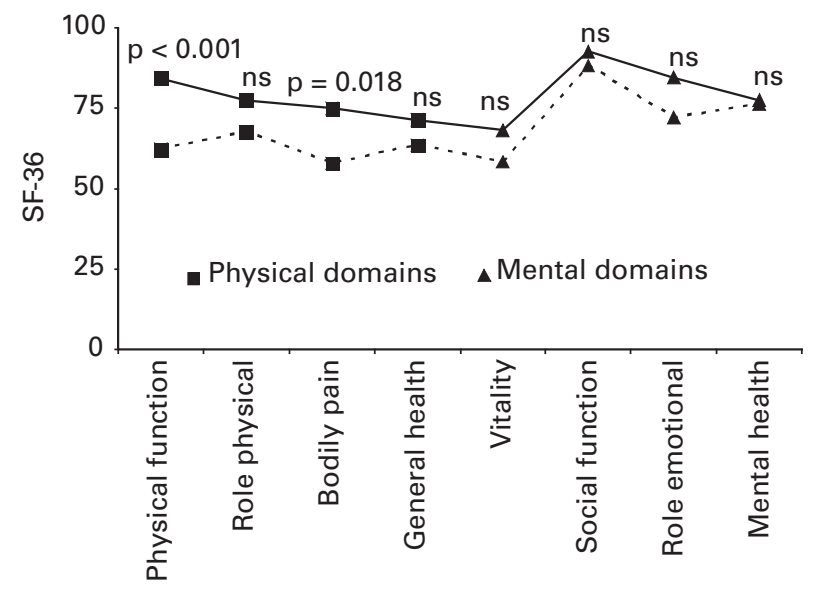

Fig. 2

Short-form 36 used to assess quality of life at the mean age of 64 years in 20 female patients treated for congenital clubfoot, and in a genderand age-matched norm group of 37 females.

than female patients in both parts of EQ-5D, the difference being significant for the VAS $(\mathrm{p}<0.001)$.

Male patients. These patients scored as having a better quality of life than the male norm group in both EQ-5D index $(p=0.027)$ and VAS $(p=0.013)$. When subdivided into the five subscales of mobility, self-care, usual activities, pain/discomfort and anxiety/depression, there was no significant difference $(\mathrm{p}>0.05)$ between the patients and the norms, except for anxiety/depression, where the male patients had significantly fewer individuals who considered themselves to have some or extreme problems (four of 63, $6.3 \%$ ) compared to the proportions in the male norm group ( 80 of $376,21.2 \%, p=0.007$ ).

Female patients. These patients scored worse than the female norm group according to both EQ-5D index and VAS scores, with a significant difference in the VAS score $(\mathrm{p}<0.001)$. There were two subsets where the proportion of female patients scoring themselves as having some or extreme problems was significantly higher than in the norm group. For mobility, the proportion in the patient group was nine of $20(45.0 \%)$ compared to 48 of 393 in the norm group $(12.2 \%, \mathrm{p}<0.001)$. For usual activities the corresponding proportion in the patient group was seven of $20(35.0 \%)$ and in the norm group (49 of 393) $(12.5 \%$, $\mathrm{p}=0.006)$. In the remaining three subscales there was no significant difference between the female patients and the female norm group.

AAOS Foot and Ankle questionnaire. The overall response rate was 81 of $89(91 \%)$ for the Core Scale and 65 of $89(73.0 \%)$ for the Shoe Comfort Scale. Both male and female patients had a worse outcome on the Core Scale than their corresponding male $(\mathrm{p}=0.002)$ and female norm groups $(\mathrm{p}<0.001)$. On the Shoe Comfort Scale both male and female patients had poorer results than their corresponding norm groups, the difference being significant for men $(\mathrm{p}<0.001)$ but not for women $(\mathrm{p}=0.104)$. The male patients were doing significantly better than the female patients according to the Core Scale $(\mathrm{p}<0.001)$, but not according to the Shoe Comfort Scale $(\mathrm{p}=0.061)$. There was no difference in outcome for unilateral or bilateral clubfoot, in either male or female patients.

There was a significant correlation for all patients between the SF-36 physical component summary score and 


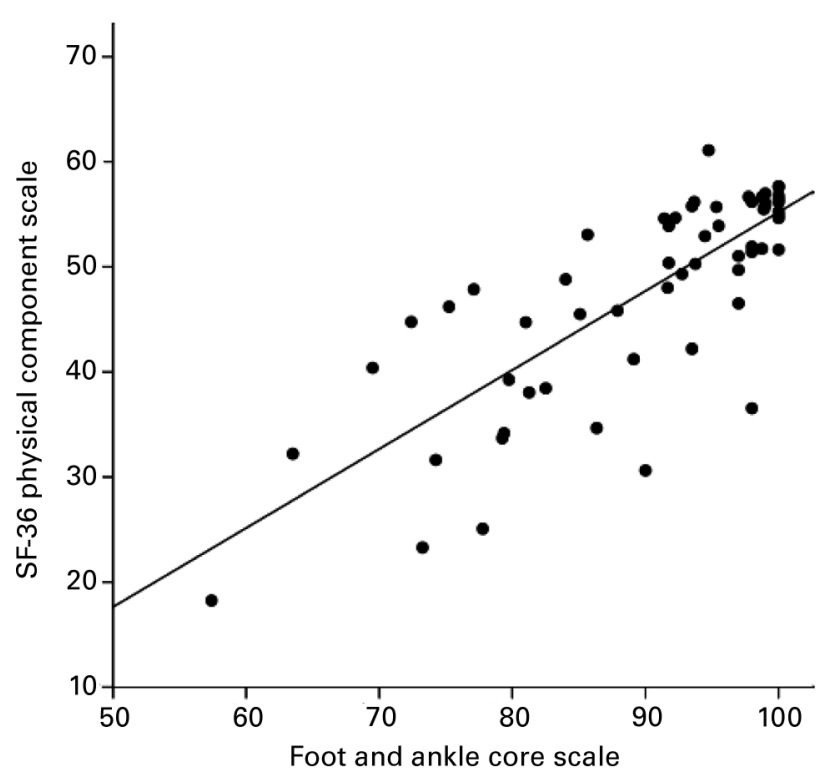

Fig. $4 a$

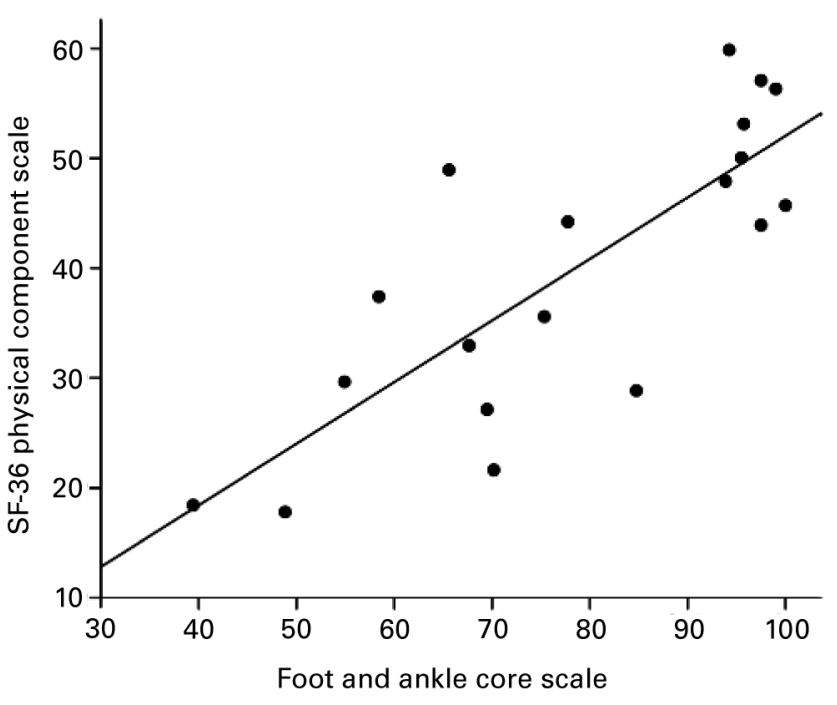

Fig. 4c

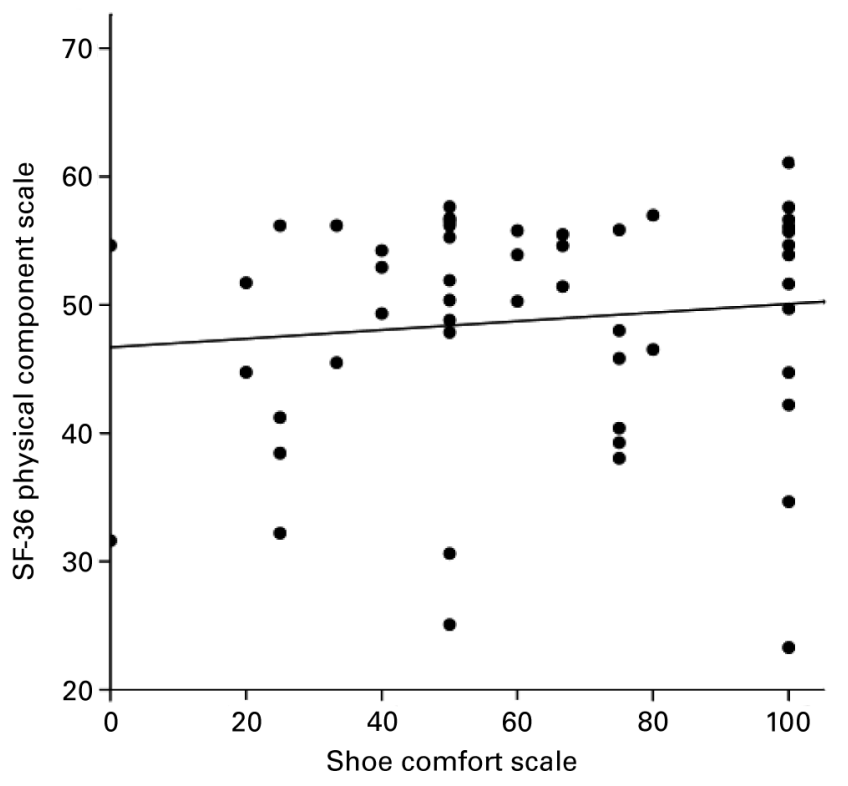

Fig. $4 \mathrm{~b}$

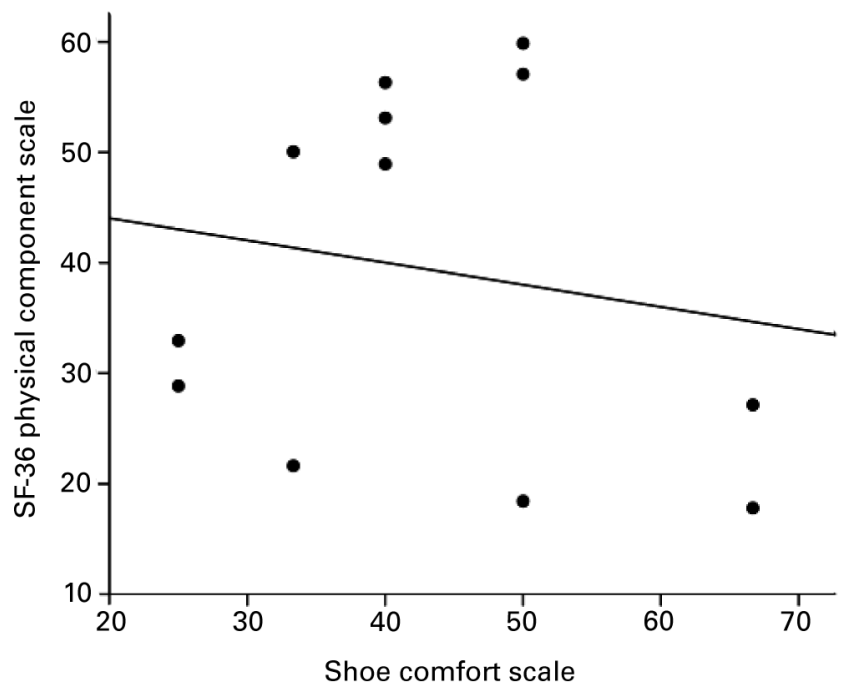

Fig. $4 d$

Scatterplots showing correlation between short-form (SF)-36 physical component scale and a) American Academy of Orthopaedic Surgeons (AAOS) Foot and Ankle Questionnaire (Core Scale) and b) AAOS Shoe comfort scale, c) Foot and Ankle Core Scale and d) AAOS Shoe comfort scale.

the AAOS Core Scale $(\mathrm{p}<0.001)$ in both groups (Figs $4 \mathrm{a}$ and $4 \mathrm{c})$. However, no correlation was found for male or female patients between SF-36 physical component summary score and AAOS Shoe Comfort Scale $(\mathrm{p}=0.447$ and $p=0.596$, respectively (Figs $4 b$ and $4 d$ ). Also, no correlation was found, for either male or female patients between SF-36 mental component summary score and any of the two AAOS subscales ( $\mathrm{p}=0.483$ to 0.885 ).

In the male patients, both the EQ-5D index and the VAS were significantly correlated to the AAOS Core Scale $(\mathrm{p}<0.001$ for both scores). In the female patients a significant correlation was found between the VAS and the AAOS Core Scale $(p=0.004)$, but not between the Index and the AAOS Core Scale $(\mathrm{p}=0.054)$.

For the AAOS Shoe Comfort Scale there was no correlation between any of the EQ-5D subscales for either gender.

Of 39 patients who thought their treated foot/feet looked normal in $1974,{ }^{17} 25(64 \%)$ now answered that they felt their treated feet looked abnormal $(\mathrm{p}<0.001)$. Only two patients who in 1974 assessed their treated foot/feet as looking abnormal experienced a better appearance at the current follow-up. 


\section{Discussion}

The patients in this study offered a unique opportunity to review the long-term outcome after treatment of CTEV. Their mean age of 64 years make this the longest follow-up so far reported, with $93 \%$ of those still alive participating.

In order to determine whether residual foot and ankle problems influenced their quality of life, three validated questionnaires were used to make the evaluation as comprehensive as possible. Although such self-reported questionnaires provide valuable structured information from the patient's perspective, ${ }^{25}$ one drawback with generic questionnaires is that their broad scope prevents in-depth inquiry, and this was why the foot-specific questionnaire was included.

The impact on function of the foot and ankle was clearly revealed, as both male and female patients had lower scores on the Core Scale than their corresponding norm groups. The same scale indicated that female patients had more problems than did males. On the Shoe Comfort scale there was no difference between female patients and the female norm group ( $\mathrm{p}=0.089)$, whereas the male patients scored worse than the male norm group $(\mathrm{p}<0.001)$.

Gender differences for foot and ankle function in the patient groups, compared to the norm groups in which no such differences were identified, was difficult to explain. It could be that female patients had more severe deformities initially, although a similar number of operations was performed on both genders. Another reason for a gender difference might be that female patients experienced more problems from unilateral than from bilateral involvement, but we found no data to support this. There was no obvious evidence that female patients had more difficulties in finding comfortable shoes as the Shoe Comfort Scale showed no difference between the female patients and the female norm group, or between the female and male patients. Hence, no valid explanation for the gender difference in specific foot and ankle problems can be offered, although the general findings of limitation in foot and ankle function in both genders concur with those of previous long-term follow-up studies. ${ }^{3,12,13,16}$

Both the SF-36 and the EQ-5D revealed lower scores in female patients than in either the male patients or the female norm group. The SF-36 outcome was worse in the female patients in seven of the eight domains compared to male patients, and in two of the eight domains compared to norms. The physical component summary score was lower in the female patients than in the female norm group, but no difference was found in the mental component summary score between female patients and the female norm group. This outcome was consistent with a report from Dobbs et al, ${ }^{3}$ who demonstrated physical impairment but a normal mental summary SF-36 score in patients treated for CTEV.

Male patients reported a better quality of life, not only compared to female patients, but also than the male norm group. There are no convincing explanations for these findings, although it is possible that males with idiopathic clubfoot adapt to their situation better than females, and this could be supported by the finding that the mental component summary score was higher in male patients than in the male norm group.

The positive correlation between the male and the female patients and the AAOS Core Scale and the four physical domains of SF-36 indicated that at least the physical aspects of quality of life were influenced by residual foot and ankle problems. However, as no correlation between the Shoe Comfort Scale and the four physical domains was found in either males or females, this suggested that shoe problems were not a negative influence on the ability to live a physically active life.

It was not possible to undertake a detailed comparison of our findings with those of Bjönness ${ }^{15}$ as different methods of evaluation were used. He concluded that the patients "managed themselves well with relatively minor deviations from the normal population with regard to work, sports and social adaptability". When comparing the patients' assessment of the appearance of their feet between Bjönness and the current study, it seems that some deterioration had occurred.

Among several limitations of this study, as in most retrospective studies of CTEV, is the lack of a primary classification of the severity of the foot deformities, as proposed for instance by Dimeglio et $\mathrm{al}^{26}$ and Pirani et al. ${ }^{27}$ Furthermore, it was not possible to evaluate whether common clinical measures correlated with patient-reported outcomes. Nevertheless, we believe the questionnaires provided new and useful data and we agree with authors ${ }^{3,13}$ who argue for generic instruments providing ratings across various disorders, thereby giving complementary information on disease-specific health status.

Our results indicate that, in patients aged 60 years or above who had been treated for CTEV, females reported more negatively on physical aspects of quality of life than did males, and both genders experienced a negative impact on foot and ankle function compared to matched norm groups.

No benefits in any form have been received or will be received from a commercial party related directly or indirectly to the subject of this article.

\section{References}

1. Wallander H, Hovelius L, Michaelsson K. Incidence of congenital clubfoot in Sweden. Acta Orthopaedica 2006;776:847-52.

2. Aronson J, Puskarich CL. Deformity and disability from treated clubfoot. J Pediatr Orthop 1990;10:109-19.

3. Dobbs MB, Nunley R, Schoenecker PL. Long-term follow-up of patients with clubfeet treated with extensive soft-tissue release. J Bone Joint Surg [Am] 2006;88-A:986-96.

4. Ponseti IV. Relapsing clubfoot: causes, prevention, and treatment. lowa Orthop J 2002;22:55-6.

5. Morcuende JA, Dolan LA, Dietz FR, Ponseti IV. Radical reduction in the rate of extensive corrective surgery for clubfoot using the Ponseti method. Pediatrics 2004;113:376-80

6. Dietz FR. Treatment of a recurrent clubfoot deformity after initial correction with the Ponseti technique. Instr Course Lect 2006;55:625-9.

7. Harvey AR, Uglow MG, Clarke NM. Clinical and functional outcome of relapse surgery in severe congenital talipes equinovarus. J Pediatr Orthop B2003;12:49-55.

8. Atar D, Lehman WB, Grant AD. Complications in clubfoot surgery. Orthop Rev 1991;20:233-9. 
9. Huber H, Galantay R, Dutoit M. Avascular necrosis after osteotomy of the talar neck to correct residual club-foot deformity in children: a long-term review. J Bone Joint Surg [Br] 2002;84-B:426-30.

10. Koureas G, Rampal V, Mascard E, Seringe R, Wicart P. The incidence and treatment of rocker bottom deformity as a complication of the conservative treatment of idiopathic congenital clubfoot. J Bone Joint Surg [Br] 2008;90-B:57-60.

11. Crawford AH, Gupta AK. Clubfoot controversies: complications and causes for failure. Instr Course Lect 1996;45:339-46.

12. Ippolito E, Farsetti P, Caterini R, Tudisco C. Long-term comparative results in patients with congenital clubfoot treated with two different protocols. J Bone Joint Surg $[A m] 2003 ; 85-A: 1286-94$

13. Cooper DM, Dietz FR. Treatment of idiopathic clubfoot: a thirty-year follow-up note. J Bone Joint Surg [Am] 1995;77-A:1477-89.

14. Laaveg SJ, Ponseti IV. Long-term results of treatment of congenital club foot. $J$ Bone Joint Surg [Am] 1980;62-A:23-31.

15. Bjönness T. Medfödd klumpfot. Department of Orthopaedics. Vol. PhD. Gothenburg: Gothenburg, 1974:61.

16. Hutchins PM, Foster BK, Paterson DC, Cole EA. Long-term results of early surgical release in club feet. J Bone Joint Surg [Br] 1985;67-B:791-9.

17. Bjönness T. Congenital clubfoot: a follow-up of 95 persons treated in Sweden from 1940-1945 with special reference to their social adaptation and subjective symptoms from the foot. Acta Orthop Scand 1975;46:848-56
18. Sullivan MK, Karlsson J, Taft C, Ware JE. SF-36 hälsoenkät: svensk manual och tolknonsguide, 2: a upplagan (Swedish Manual and Interpretation guide, 2nd ed). Sahlgren University Hospital, 2002.

19. Ware JE Jr, Sherbourne CD. The MOS 36-item short-form health survey (SF-36). I: conceptual framework and item selection. Med Care 1992;30:473-83.

20. Brooks R. Euro0ol: the current state of play. Health Policy 1996;37:53-72.

21. Dolan $\mathbf{P}$, Gudex C, Kind $\mathbf{P}$, Williams $\mathbf{A}$. The time trade-off method: results from a general population study. Health Economics 1996:5:141-54.

22. Burstrom K, Johannesson M, Diderichsen F. Swedish population health-related quality of life results using the EQ-5D. Quality of Life Research 2001;10:621-35.

23. Johanson NA, Liang MH, Daltroy L, Rudicel S, Richmond J. American Academy of Orthopaedic Surgeons lower limb outcomes assessment instruments: reliability, validity, and sensitivity to change. J Bone Joint Surg [Am] 2004;86-A:902-9.

24. Eriksson E, Nordlund A. Health and heath related quality of life as measured by the E0-5D and the SF-36 in South East Sweden: results from two population surveys. Linköping: Folkhälsoventenskapligt Centrum, 2002

25. Bowling A. Measuring health: a review of quality of life measurement scales. Third ed. Berkshire: Buckingham Open University Pr, 2005:211.

26. Dimeglio A, Bensahel H, Souchet P, Mazeau P, Bonnet F. Classification of clubfoot. J Pediatr Orthop B 1995;4:129-36.

27. Pirani S, Outerbridge H, Moran M, Sawatsky B. A method of evaluating the virgin clubfoot with substantial inter-observer reliability. POSNA Miami, Florida, 1995. 